OPEN ACCESS

Edited by: Jeremiah Johnson, The University of Tennessee, Knoxville, United States

Reviewed by: Roy Martin Roop II, East Carolina University, United States Jerod Skyberg, University of Missouri, United States

*Correspondence: Angel A. Oñate aonate@udec.cl

Specialty section: This article was submitted to Molecular Bacterial Pathogenesis, a section of the journal Frontiers in Cellular and Infection Microbiology

Received: 20 December 2019 Accepted: 03 April 2020 Published: 28 April 2020

Citation:

Coloma-Rivero RF, Gómez L, Alvarez F, Saitz W, del Canto F, Céspedes $S$, Vidal $R$ and Oñate $A A$ (2020) The Role of the Flagellar

Protein FlgJ in the Virulence of Brucella abortus.

Front. Cell. Infect. Microbiol. 10:178 doi: 10.3389/fcimb.2020.00178

\section{The Role of the Flagellar Protein FlgJ in the Virulence of Brucella abortus}

\author{
Roberto F. Coloma-Rivero ${ }^{1}$, Leonardo Gómez ${ }^{1}$, Francisco Alvarez ${ }^{1}$, Waleska Saitz ${ }^{1,2}$, \\ Felipe del Canto $^{2}$, Sandra Céspedes ${ }^{1,2}$, Roberto Vidal ${ }^{2}$ and Angel A. Oñate ${ }^{1 *}$ \\ ${ }^{1}$ Laboratory of Molecular Immunology, Department of Microbiology, Faculty of Biological Sciences, Universidad de \\ Concepción, Concepción, Chile, ${ }^{2}$ Microbiology and Mycology Program, Institute of Biomedical Sciences, Faculty of \\ Medicine, University of Chile, Santiago, Chile
}

Brucella abortus is a facultative intracellular pathogen that causes a zoonosis called brucellosis. This disease leads to abortion and infertility in cattle, and diverse complications in humans. B. abortus is a successful intracellular bacterium that has developed the ability to evade the host's immune system and it replicates in professional and non-professional phagocytic cells, persisting in the different tissues, and organs of its hosts. It has been described that Brucella expresses a polar flagellum under certain conditions, but its function is still unknown. In this study we evaluated the role of the FlgJ, a protein, presumably a peptidoglycan hydrolase involved in flagellum formation and in the virulence of $B$. abortus strain 2308. B. abortus $2308 \Delta f l g J$ mutant and complemented strains were constructed to study the function of the FlgJ protein in the context of the virulence of this pathogen in in vitro and in vivo assays. The results showed that the elimination of the flg J gene delays the growth rate of $B$. abortus in culture, reduces its intracellular survival capacity in professional and non-professional phagocytic cells, rendering it unable to escape from the endocytic route and not reaching the endoplasmic reticulum. It also negatively affects their persistence in BALB/c mice. Functionally, the $B$. abortus $2308 \mathrm{flg} \mathrm{J}$ gene restored motility to an E. coli flg J mutant gene. Furthermore, it was discovered that the production of FlgJ protein is associated with the bacterial adherence by $B$. abortus. Therefore, although the specific function of the polar flagellum for Brucella is unknown, the data indicates that the flagellar flg $\mathrm{J}$ gene and its product are required for full virulence of $B$. abortus 2308 , since its deletion significantly reduces the fitness of this pathogen in vitro and in vivo.

Keywords: Brucella abortus, genomic island 3 (GI-3), flagellum, FlgJ protein, intracellular trafficking, virulence factors

\section{INTRODUCTION}

Brucella abortus is a Gram-negative bacterium that causes of bovine brucellosis, a global zoonotic disease affecting cattle and humans (Corbel, 1997). This pathogen can infect humans through direct contact with infected animals, the ingestion of contaminated food or by the inhalation of aerosolized particles contaminated with B. abortus (De Figueiredo et al., 2015). In the mucosal membranes, this bacterium can be captured by phagocytic cells, where it survives to the intracellular microbicide mechanisms due to several virulence factors such as its atypical lipopolysaccharide (LPS), $\beta 1,2$-glucans, the two-component system BvrR/BvrS, or the type 4 secretion system virB (Carvalho et al., 2010). These virulence factors allow it to inhibit the phagosome-lysosome 
fusion and to escape toward the endoplasmic reticulum to develop its replicative niche (Zygmunt et al., 2012; AltamiranoSilva et al., 2018). This capacity for intracellularly survival in phagocytic cells is fundamental to reaching several tissues and organs, producing a systemic infection, which in humans present as undulant fever, night sweats, insomnia and headache, followed by a chronic phase where this bacterium is localized in various tissues and organs causing hepatitis, neurobrucellosis, or endocarditis (Galinska and Zagórski, 2013; Dean et al., 2014; Young et al., 2014). In cattle, brucellosis produces mainly abortion and infertility in females and males, respectively (D’Anastasio et al., 2011).

B. abortus is a bacterium traditionally described as nonmotile; however, it has all the flagellar genes for synthesis of a functional flagellum contained in its genome (Abdallah et al., 2003). This flagellum was reported in Brucella melitensis $16 \mathrm{M}$ as a polar and sheathed apparatus, which is expressed under precise in vitro conditions and during infection (Fretin et al., 2005). Mutant strains for flagellar proteins such as $f l i F, f l h A, \operatorname{mot} B$, or $f l g E$ were shown to be required for the intracellularly survival of B. melitensis in mouse spleen (Fretin et al., 2005). The bacterial flagellum has commonly been associated with several functions that differ between bacteria or the bacterial life cycle: a scourge can, e.g., participate in biofilm formation or adherence (Haiko and Westerlund-Wikström, 2013). Several bacteria colonize different surfaces and invade susceptible hosts causing chronic infections that grow predominantly as biofilms (Hall-Stoodleyl and Stoodley, 2009; Burmølle et al., 2010). The biofilms are extracellular polymeric substances (EPS) self-produced by microorganisms, which are mainly polysaccharides, proteins, nucleic acids and lipids that mediate their adhesion to diverse surfaces and allow intense interactions among bacteria (cellcell communication, competition, cooperation or horizontal gene transfer) (Flemming and Wingender, 2010).

The underlying molecular mechanisms of B. abortus flagellum or biofilm formation has been poorly studied. However, it has been demonstrated that quorum-sensing (QS) genes, vjbR and blxR, transcriptional regulator is involved in Brucella virulence (Rambow-Larsen et al., 2008). One of these, VjbR, is required by $B$. melitensis for the transcription of the type IV secretion system and expression of various flagellar genes ( $f l i F, f l h A, \operatorname{mot} B$, or $f l g E$ ), which contribute its virulence in mice (Delrue et al., 2005; Fretin et al., 2005). Interestingly, B. abortus contains the flagellar protein FlgJ encoded out of a flagellar gene cluster, specifically in the open reading frame (ORF) BAB1_0260 of the B. abortus genomic island 3 (GI-3), a GI constituted by several ORFs, some of them involved in survival, replication and immune evasion (Rajashekara et al., 2004; Cirl et al., 2008; Salcedo et al., 2008; Céspedes et al., 2012; Ortiz-Román et al., 2014; Gómez et al., 2016, 2018). This protein is and ortholog to FlgJ of E. coli and Salmonella enterica serovar Typhimurium, and it plays an important role in the flagellum assembly. FlgJ is characterized by a N-terminal half with function scaffold or cap essential for flagellar rod assembly and a C-terminal half with peptidoglycan (PG) hydrolyzing activity that facilitates rod penetration into the PG (Nambu et al., 1999; Hirano et al., 2001). In E. coli K-12 strain, this peptidoglycan hydrolase FlgJ has muramidase activity by glucosaminidase or Lysozyme subfamily 2 (LYZ2) domains which hydrolyses the peptidoglycan layer and assembly the rod structure in the periplasmic space (Marchler-Bauer et al., 2017). Their function hydrolyzing is generated by glucosaminidase domains of the Carbohydrate Active Enzyme (CAZy) family GH73 facilitating the passage of the flagellum by the cleaving of the $\beta-1,4$ glycosidic bond between $\beta$ - $\mathrm{N}$-acetylglucosamine and $\beta$ $\mathrm{N}$-acetylmuramic acid sugars comprising the glycan strands of the PG (Hirano et al., 2001; Zaloba et al., 2016).

Although the importance of the FlgJ protein in the physiology or pathogenicity of Brucella has not been described, it could potentially be involved in virulence because the vaccination of mice with recombinant FlgJ protein conferred significant protection levels against infection with $B$. abortus strain $544(\mathrm{Li}$ et al., 2012). In general, the process of bacterial infection includes adhesion, invasion, escape of infected cells and modulation of the immune response that contributes to persistence inside the host, this kind of interactions with the hosts is linked to the function expression flagella in pathogenic and symbiotic bacteria (Josenhans and Suerbaum, 2002). The expression of Brucella flagellar proteins could play a role in these infection processes or act directly in the growth and division of this bacterium, and thus fulfill important roles in the physiology and interaction with their host, where these FlgJ proteins are considered important part of this process. Therefore, in the present study, the role of the flagellar protein FlgJ in the virulence of B. abortus strain 2308 was investigated. Using an isogenic B. abortus $2308 \Delta \mathrm{flgJ}$ mutant it was determined that the FlgJ protein is required for flagella function, and that this flagellum is required for full virulence in phagocytic cells and in persistence in mice.

\section{MATERIALS AND METHODS}

\section{Animals}

Ten-week old female isogenic BALB/c mice were obtained from the Instituto de Salud Pública (Santiago, Chile). The animals were kept at the Laboratory of Molecular Immunology (Department of Microbiology, Faculty of Biological Sciences, Universidad de Concepción, Chile) and after arrival were randomly distributed into experimental and control groups and allowed to acclimate. The mice were kept in a under controlled temperature and fed with commercial pellets and water ad libitum. All regulations from the Institutional Bioethics Committee of the Faculty of Biological Sciences, Universidad de Concepción, were fulfilled. The Bioethics and Safety Committee of the Faculty of Biological Sciences at the Universidad de Concepción approved this study. All efforts were made to minimize animal suffering.

\section{Cell Lines}

In this work, HeLa cells and RAW and J774.A1 macrophage cell lines obtained from the American Type Culture Collection (ATCC) were used. The cells were cultured in Dulbecco's Modified Eagle Medium (DMEM) (ThermoFisher Scientific, MA) and supplemented with 10\% fetal bovine serum (Gibco BRL, USA) and antibiotic-antimycotic solution (100 IU of penicillin, $100 \mu \mathrm{g} / \mathrm{mL}$ of streptomycin, and $0.25 \mu \mathrm{g} / \mathrm{mL}$ of amphotericin, Sigma-Aldich Co., MO). 
TABLE 1 | Bacteria and plasmids used in this study.

\begin{tabular}{|c|c|c|}
\hline Strains or plasmids & Characteristics & Reference \\
\hline Brucella abortus 2308 & Wild-type, smooth, virulent strain & Laboratory stock \\
\hline B. abortus $2308 \Delta f l g J$ & $\begin{array}{l}\text { B. abortus 2308, deleted in the } \\
\text { BAB1_0260 ORF (flgJ) }\end{array}$ & This work \\
\hline $\begin{array}{l}\text { B. abortus } 2308 \Delta \text { flgJ } \\
\text { (pVB1-flgJ) }\end{array}$ & $\begin{array}{l}\text { B. abortus } \Delta \text { flgJ, containing } \\
\text { plasmid pVB1-flgJ, } \mathrm{Am}^{r}, \mathrm{Km}^{\mathrm{r}}\end{array}$ & This work \\
\hline B. abortus2308-gfp & $\begin{array}{l}\text { Wild-type strain, containing } \\
\text { plasmid pAKgfp1, Amp }{ }^{r}\end{array}$ & This work \\
\hline $\begin{array}{l}\text { B. abortus } 2308 \\
\Delta \text { flgJ-gfp }\end{array}$ & $\begin{array}{l}\text { B. abortus } \Delta f l g J \text { containing } \\
\text { plasmid pAKgfp1, Amp }{ }^{r}, \mathrm{Km}^{r}\end{array}$ & This work \\
\hline $\begin{array}{l}\text { B. abortus } 2308 \Delta f l g J \\
\text { (pVB1-flgJ)-gfp }\end{array}$ & $\begin{array}{l}\text { B. abortus } \Delta f l g J(p \vee B 1-f l g J) \\
\text { containing plasmid pAKgfp } 1 \text {, } \\
\mathrm{Am}^{r}, \mathrm{Km}^{\mathrm{r}}\end{array}$ & This work \\
\hline Escherichia coli DH5a & $\begin{array}{l}F-\Phi 80 l a c Z \Delta M 15 \\
\Delta(\text { lacZYA-argF) U169 recA1 } \\
\text { endA1 hsdR17 multiplicity of } \\
\text { plasmids }\end{array}$ & Invitrogen \\
\hline E. coli K-12 & $\begin{array}{l}(r K-, \text { mK+) phoA supE } 44 \lambda- \\
\text { thi-1 gyrA96 relA1 }\end{array}$ & Invitrogen \\
\hline E. coli $\Delta$ flgJ & E. coli deleted in the flgJ gene & This work \\
\hline E. coli $\Delta f l g J(p \vee B 1-f l g J)$ & $\begin{array}{l}\text { E. coli } \Delta \text { flgJ complemented with } \\
\text { vector pVB1-flgJ }\end{array}$ & This work \\
\hline pSIM7/pSIM9 & $\begin{array}{l}\text { Broad-host-range cloning vector, } \\
\text { Lambda Red Recombinase } \\
(\lambda \text {-Red) }\end{array}$ & Laboratory stock \\
\hline pKD4 & $\mathrm{Km}^{r}$ sequence & Laboratory stock \\
\hline pVB1 & $\begin{array}{l}\text { Cloning vector for PCR product } \\
\text { expression }\end{array}$ & Laboratory stock \\
\hline pVB1-flgJ & $\begin{array}{l}\text { Recombinant vector codifying of } \\
\text { B. abortus } 2308 f l g J \text { gene }\end{array}$ & This work \\
\hline pAKgfp1 & $\begin{array}{l}\text { Plasmid codifying of green } \\
\text { fluorescence protein (GFP) } \\
\left(\text { Amp }^{r}\right)\end{array}$ & Addgene \\
\hline
\end{tabular}

$A m^{r}$ - Ampicillin resistance; $\mathrm{Km}^{r}$ - Kanamycin resistance.

\section{Bacterial Strains and Culture Conditions}

The bacterial strains used in this study are listed in Table $\mathbf{1 .}$ Escherichia coli and B. abortus strains were cultured in Luria Bertani (LB), Terrific broth or Brucella broth (Becton, Dickinson and Company, BD, Sparks, MD21152 USA), respectively. All B. abortus strains were cultured for $48-72 \mathrm{~h}$ at $37^{\circ} \mathrm{C}$ under microaerophilic conditions and supplemented with antibiotics. Furthermore, E. coli strains were cultured in Terrific broth medium (BioWorld, Ohio, USA) or agar for $24 \mathrm{~h}$ at $37^{\circ} \mathrm{C}$. When was necessary, the bacterial medium was supplemented with 50 $\mu \mathrm{g} / \mathrm{ml}$ of kanamycin, $100 \mu \mathrm{g} / \mathrm{ml}$ of ampicillin or $30 \mu \mathrm{g} / \mathrm{ml}$ of chloramphenicol (Ortiz-Román et al., 2014).

\section{Construction of flgJ Mutants in B. abortus and $E$. coli K12}

In order to generate a $B$. abortus $\Delta$ flgJ mutant, a modification of the phage lambda $(\lambda)$ red system we used (Datsenko and

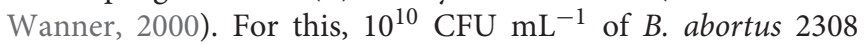
were transformed by electroporation with $200 \mathrm{ng}$ of recombinant plasmid pSIM7 (Sharan et al., 2009) and incubated at $30^{\circ} \mathrm{C}$ for $72 \mathrm{~h}$ in brucella broth supplemented with $30 \mu \mathrm{g} / \mathrm{mL}$ of
TABLE 2 | Primers used in this study within the genome framework of $B$. abortus 2308.

\begin{tabular}{lll}
\hline Name Sequence & $\begin{array}{l}\text { Restriction } \\
\text { enzyme }\end{array}$ \\
\hline
\end{tabular}

flgJ $\mathrm{Km}^{\mathrm{r}}(\mathrm{F})$ TATATCTGATCCGGGTITTCA NA

CCGAAGAAAAGCAAGC

CTTGAAAGAGCAGGCCCG

CAAGAAAGGTACTTCGCTT

TCCGGCTTGATCCGGGAT

GCTGTTCTTGATGCGCCTTC

AACTTCGACAGCGGGATACGAT

GGAGTGTGGTCATGA

GTGTAGGCTGGAGCTGCTTC*

flgJ $\mathrm{Km}^{r}(\mathrm{R})$ AACGTCTITCGCCAATTCGT NA

CGGGCCTACTGTACCGT

CATTCGAGAATGACTGATTGG

CAAACCGCTITTGCAA

TGCCGACCGCATTACGTCTG

GAGACGTGCCCTCTGGG

AATTCGGCTATCGTGCCGTCTG

GAAGCTCTACTTCAAT

CATATGAATATCCTCCTTAG*

flgJ (F) AAGAAAAGCAAGCCTTGAAAGAG

flgJ (R) CATGACCACCTCCATCCATCGTATC

flg」 ACTGACATATGACACCTATCGG Ndel

flgJ AGGGATCCTCATTCGAAATC BamHI

CAACAGAAAT

ACCAGTCTGC

*The Sequence used to amplify $\mathrm{Km}^{r}$ is underlined.

${ }^{\dagger} \mathrm{Ndel}$ and BamHI, restriction endonuclease cleavage sites are underlined.

$N A$, non-availability; (F), Forward; (R), Reverse.

chloramphenicol. Transformants were incubated at $42^{\circ} \mathrm{C}$ for $30 \mathrm{~min}$ to induce expression of the $\lambda$ red recombinase (Halling, 1998) and to allow the kanamycin resistance cassette $\left(\mathrm{Km}^{\mathrm{r}}\right)$, previously amplified by PCR from plasmid pKD4 (Table 2) to exchange by homologous recombination. The PCR product was purified and electroporated in $10^{10} \mathrm{CFU} / \mathrm{mL}$ of B. abortus 2308 previously transformed with pSIM7 and cultured at $37^{\circ} \mathrm{C}$ for $72 \mathrm{~h}$ in brucella agar plates supplemented with $50 \mu \mathrm{g} / \mathrm{mL} \mathrm{Km}$ for selection of mutants. Colonies were screened by PCR using primers $f l g J \mathrm{~km}^{\mathrm{r}}(\mathrm{FW})$ and $f l g J \mathrm{~km}^{\mathrm{r}}$ (RV) (Table 2). In order to ensure that the possible changes observed were only in the mutant strain $\Delta f l g J$, this strain was supplemented with the respective gene linked to the vector $\mathrm{pVB1}$. Briefly, flgJ gene was amplified from B. abortus 2308 genomic DNA using primers that carry cut sequences for the restriction enzymes NdeI and BamHI at their ends (Table 2). Then, the amplified fragment was purified and cloned into pVB1 using the enzyme T4 DNA ligase to generate the pVB1-flgJ construct. The plasmid pVB1flgJ was electroporated into B. abortus $2308 \Delta$ flgJ, generating the strain complemented with B. abortus $2308 \Delta f l g J$ (pVB1-flgJ) (Ortiz-Román et al., 2014). It should be mentioned that the $E$. coli used in this work was mutated using the same protocol described previously.

\section{Growth Curves}

To determine whether the mutation of the flgJ gene affected the growth rate of $B$. abortus 2308, growth curves for $B$. abortus 
$2308 \Delta f l g J$ and B. abortus $\Delta$ flgJ (pVB1-flgJ) were performed and compared to wild type B. abortus 2308 . To this end, $100 \mu \mathrm{l}$ of each strain at an optical density at $600 \mathrm{~nm}\left(\mathrm{OD}_{600}\right)$ of 0.5 were added into flasks with brucella broth and grown with agitation $(150 \mathrm{rpm})$ at $37^{\circ} \mathrm{C}$. Aliquots of these cultures were taken every $12 \mathrm{~h}$ for a period of $144 \mathrm{~h}$ and their $\mathrm{OD}_{600}$ was measured.

\section{Transcomplementation and Motility Assays}

To demonstrate the role of the B. abortus flgJ gene in flagellar function, a mutant $E$. coli strain K-12 for the flgJ gene (E. coli $\Delta f l g J)$ was constructed, which was complemented with the $B$. abortus $2308 \mathrm{flgJ}$ gene, yielding E. coli $\Delta$ flgJ (pVB1-flgJ). The function of this flagellar protein in the motility of the constructs was evaluated using Motility-Indole-Ornithine (MIO) medium (Becton Dickinson) for $24 \mathrm{~h}$ at $37^{\circ} \mathrm{C}$.

\section{Screening for Biomass Production}

To assess the participation of the FlgJ protein in the formation of adherent biomass, $100 \mu \mathrm{l}\left(1.5 \times 10^{8} \mathrm{CFU} \mathrm{m}^{-1}\right)$ of Brucella abortus 2308, Brucella abortus $2308 \Delta$ flgJ and the Brucella abortus $\Delta f l g J$ (pVB1-flgJ) were each grown independently in brucella broth, using E. coli strain K-12 (Almirón et al., 2013) as an external control. These strains were added to 96-well microplates. The plates were incubated for 7 days at $37^{\circ} \mathrm{C}$ without shaking them, and non-adherent bacteria were removed by washing three times with sterile physiological saline solution $(0.9 \% \mathrm{NaCl}, \mathrm{w} / \mathrm{v})$. The adherent bacteria (biomass adhered) were then stained for $45 \mathrm{~min}$ with a solution of $1 \%$ Crystal Violet (Sigma-Aldrich, w/v). After washing and air drying, the stain bound to the adherent cells was dissolved into ethanol and the adherent biomass, per each well, was measured as the optical density (OD $550 \mathrm{~nm}$ ) as an indirect index of adherent biomass formation, using a Multiskan GO Microplate Spectrophotometer (Thermo Scientific Lab.) (Stepanović et al., 2007; Spanò et al., 2016; Chai et al., 2017). All the experiments in this study were performed three times; the supernatant was not measured and it was not verified that the cell bodies present in it had any growth activity.

\section{Intracellular Survival of $B$. abortus Strains}

Intracellular replication of $B$. abortus 2308, B. abortus 2308 $\Delta f l g J$ and B. abortus $2308 \Delta f l g J$ (pBV1-flgJ) was evaluated in non-professional (epithelial HeLa) and professional (J774.A1 macrophages) phagocytic cell lines culture in supplemented DMEM medium in a $5 \% \mathrm{CO}_{2}$ atmosphere at $37^{\circ} \mathrm{C}$. In parallel, all $B$. abortus strains were cultured in brucella broth for $48 \mathrm{~h}$ and suspended at a concentration of $10^{7} \mathrm{CFU} \mathrm{m}{ }^{-1}$ of DMEM (supplemented with $10 \%$ fetal calf serum and $2 \mathrm{mM}$ glutamine, free of antibiotics). These bacterial suspensions were added to HeLa or J774.A1 cells at a 500:1 or 50:1 multiplicity of infection (MOI), respectively. After $1 \mathrm{~h}$ of incubation, the cell monolayer was washed with phosphate-buffered saline (PBS) and incubated for $60 \mathrm{~min}$ with fresh media, supplemented with $50 \mu \mathrm{g} \mathrm{mL}-1$ gentamicin and $100 \mu \mathrm{g} \mathrm{mL} \mathrm{m}^{-1}$ streptomycin for extracellular bacteria elimination. At 4, 24, 48, and $72 \mathrm{~h}$ post-infection, the cells were washed with PBS and lysed with $1 \mathrm{~mL}$ of $0.1 \%$ Triton X-100. The cellular lysate was serially diluted and the number of CFU
$\mathrm{mL}^{-1}$ was determined in brucella agar plates (Céspedes et al., 2011, 2012).

\section{Intracellular Trafficking of B. abortus 2308 $\Delta f l g J$ in Macrophages}

To visualize the intracellular trafficking of $B$. abortus strains by means of immunofluorescence techniques, they were transformed with the host-wide vector pAKgfp1 (Addgene plasmid \#16076) encoding the green fluorescent protein (GFP). Intracellular trafficking of the Brucella strains within RAW264.7 murine macrophages (MOI 50:1) were quantified in early and late endosomes and reticulum endoplasmic at 15 minutes, 4 and $12 \mathrm{~h}$ post infection (pi), respectively. Next, macrophages were fixed with $4 \%$ paraformaldehyde, washed with PBS (pH 7.4) and incubated with goat anti-EEA1 polyclonal antibodies (Santa Cruz Biotechnology, Dallas, TX, USA), specific for an early endosome marker (Early Endosome Antigen 1), rabbit anti-LAMP1 (lysosomal-associated membrane protein 1), a late endosomal marker (Santa Cruz Biotechnology, Dallas, TX, USA) and goat anti-calnexin for endoplasmic reticulum (ER) marker (Abcam, Cambridge, United Kingdom). All antibodies were diluted in PBS buffer ( $\mathrm{pH}$ 7.4) with $0.5 \%$ bovine serum albumin (BSA) and incubated in a humidity chamber for $3 \mathrm{~h}$. After this period, coverslips were washed with PBS (pH 7.4) and incubated with donkey anti-goat IgG Alexa Fluor 594 (Thermo Fisher Scientific Inc., Massachusetts, MA, USA) or donkey anti-rabbit IgG Alexa Fluor 647 as a secondary antibody (Abcam, Cambridge, UK) diluted 1:500. Finally, the samples were mounted on slides using Dako Cytomation fluorescent mounting medium (Sigma-Aldrich, St. Louis, MO, USA). The samples were observed under a Zeiss LSM 700 laser scanning confocal microscope for image acquisition (Zeiss, Oberkochen, Germany). The intracellular co-localization data and images of 1,024 X 1,024 pixels were acquired and assembled by image analysis using ImageJ software. Data are representative of at least two independent experiments.

\section{Bacterial Colonization Assay in Spleen of BALB /c Mice}

B. abortus wild-type 2308, mutant and complemented strains were used to infect mice, and the survival of bacteria in the spleen was determined (Fretin et al., 2005). Nine-weekold, pathogen-free, female BALB/c mice, the most extensively used model for studying chronic infection caused by Brucella spp. (Blocker et al., 2003), were inoculated intraperitoneally with $10^{5} \mathrm{CFU}^{-1}$ of each Brucella strain in $0.1 \mathrm{ml}$ of PBS. Two - and four -week post-infection, animals were euthanized by cervical dislocation, and their spleens were removed and homogenized in PBS. The homogenized tissues were serially diluted in PBS and plated onto Columbia agar with 5\% sheep blood (Biomerieux, USA to determine the number of CFUs per spleen (Ortiz-Román et al., 2014).

\section{Statistical Analysis}

Data analysis to establish significant differences in adherent biomass formation and intracellular trafficking between $B$. abortus $2308 \Delta$ flgJ, B. abortus $2308 \Delta$ flgJ (pVB1-flgJ) and B. 


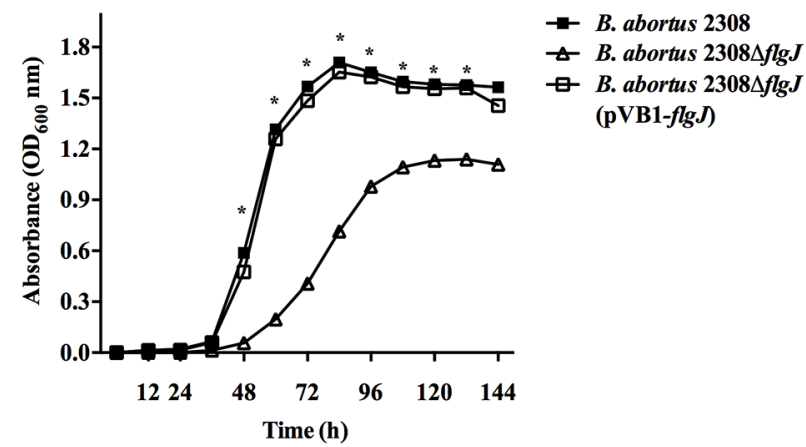

FIGURE 1 | Growth curves of B. abortus strains; B. abortus 2308 (wt), B. abortus 2308 fflgJ, and complemented 2308 $\mathrm{flgJ}$ (pBV1-flgJ). Deletion of flgJ gen in $B$. abortus 2308 results in a growth deficiency. The absorbance (optical density, OD) was measured under $600 \mathrm{~nm}$; the plotted points for each curve was measured at $12 \mathrm{~h}$ of culture. Results were expressed as mean \pm standard deviation (SD), ${ }^{\star} P<0.05$ significant.

abortus 2308 strains were analyzed by one-way ANOVA, while the intracellular survival in professional and non-professional phagocytic cells and mice infection assays were analyzed using a two-way ANOVA. Tukey's multiple comparison test analyzed all results. Values of $P<0.05$ were considered statistically significant. All the quantitative experiments were performed three times on separate days in triplicate and the results shown are the mean of those experiments.

\section{RESULTS}

\section{Growth Curve of Different B. abortus Strains}

The effect of the mutation of the flgJ gene on bacterial growth was evaluated as described above. The B. abortus $2308 \Delta$ flgJ showed a $12 \mathrm{~h}$-delay in the lag phase as compared to the wild-type strain. In addition, when observing the logarithmic growth phase of the mutant strain, it was much lower than the wt strain. B. abortus $2308 \Delta f l g J$ reached the stationary phase after $96 \mathrm{~h}$ of culture; by contrast, the wild-type strain entered the stationary phase after $72 \mathrm{~h}$ of growth. No differences were observed between the growth curves of B. abortus 2308 and B. abortus $2308 \Delta$ flgJ (pBV1-flgJ) (Figure 1). This indicates that the FlgJ protein encoding for ORF BAB1_0260 is involved in the normal growth of Brucella.

\section{Functional Evaluation of the B. abortus flgJ Gene}

The role of the flgJ gene in E. coli strain K-12 motility was evaluated using an E. coli $\Delta$ flgJ complemented with the B. abortus flgJ gene, after inoculation of MIO medium. As expected, the E. coli $\Delta$ flgJ (Figure 2B) lost its motility compared to E. coli K12 parental strain (Figure 2A). This defect was slightly rescued by transcomplementation of the flgJ gene of B. abortus 2308 (Figure 2C).

\section{Screening for Biomass Production}

Regarding the ability of the B. abortus 2308 strain to form biomass adhered in polystyrene plates at 7 days, the results showed that B. abortus $2308 \Delta$ flgJ presented a biomass

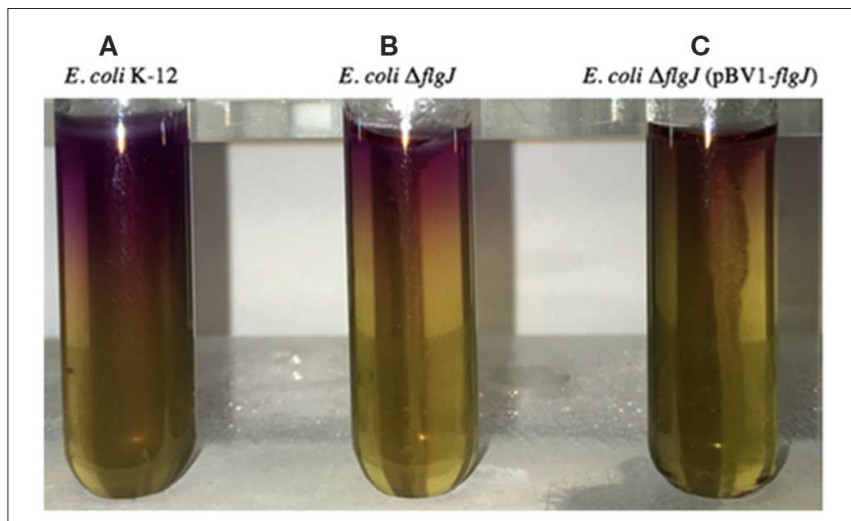

FIGURE 2 | Mobility assay of $E$. coli $\Delta$ flgJ measured using MIO medium. The lack of the flgJ gene evidences a decrease in the mobility of $E$. coli $\mathrm{K}-12$. (A) $E$. coli K-12 strain. (B) E. coli $\Delta$ flgJ strain. (C) E. coli $\Delta$ flgJ complemented with pBV1-flgJ encoding of flgJ from $B$. abortus 2,308 strain.

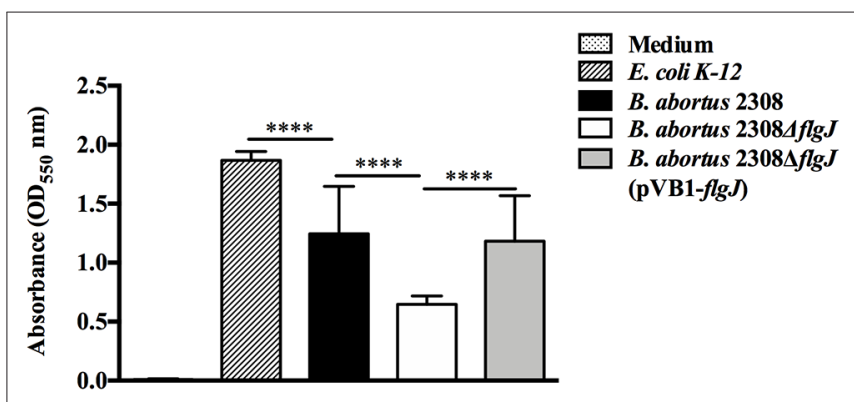

FIGURE 3 | Screening for biomass production. Quantitative measurement by absorbance to $550 \mathrm{~nm}$ of adhered biomass production in 96-well polystyrene plates, of B. abortus 2,308, B. abortus $2308 \Delta$ flgJ, and complemented $2308 \Delta f l g J$ (pBV1-flg J) in addition to E. coli K-12 as a positive control of biomass production and culture medium as a negative control. Results are expressed as means \pm standard deviation. Values of ${ }^{* \star \star \star} P<0.001$ are considered highly significant.

production measured by absorbance at $\mathrm{OD}_{550}$ significantly lower than biomass produced by B. abortus $2308 \Delta$ flgJ (pVB1-flgJ) and $B$. abortus $2308(P<0.001)$ (Figure 3). These data suggest that deletion of BAB1_0260 from B. abortus 2308 reduces its ability to form adhered biomass; therefore, the FlgJ protein could be an actively participant in the formation of biomass adhered on an inert surface.

\section{Intracellular Survival of B. abortus 2308 $\Delta f / g J$ in Non-professional and Professional Phagocytic Cells}

The effect of the deletion of BAB1_0260 ORF (flgJ gene) on the ability of $B$. abortus to infect and proliferate within phagocytic and non-phagocytic cells was studied using J774.1 macrophages and HeLa epithelial cells, respectively. We found that at $4 \mathrm{~h}$ postinfection (p.i.) of macrophage J774.1, all the Brucella strains showed a similar number of intracellular bacteria (Figure 4A). However, between 24 and $72 \mathrm{~h}$ p.i., the B. abortus $2308 \Delta f l g J$ strain was recovered from macrophages approximately in $2 \log _{10}$ CFU ml ${ }^{-1}$ less than B. abortus 2308 or B. abortus $\Delta$ flgJ (pVB1flgJ) $(P<0.05)$. When bacterial internalization and survival 

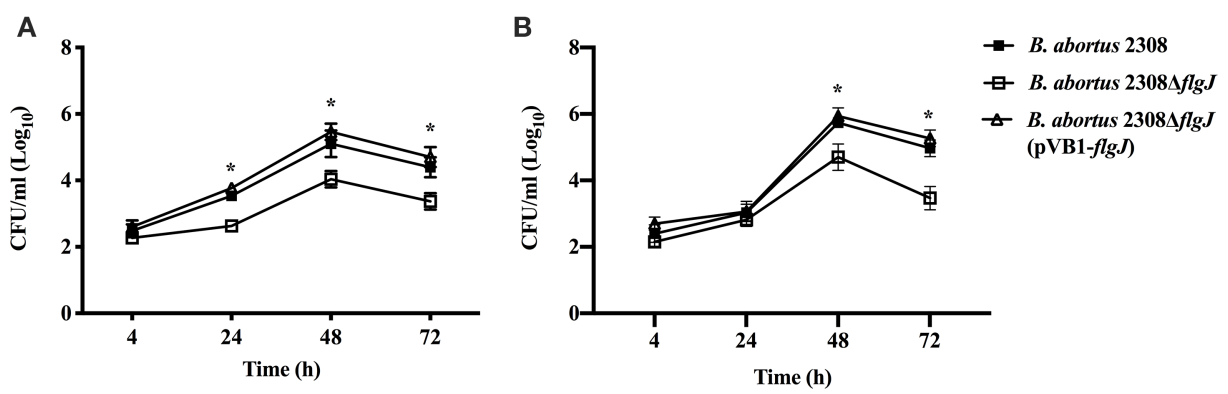

FIGURE 4 | Intracellular survival of B. abortus $\Delta$ flg J in professional and non-professional phagocytes. (A) J774.A1 macrophages were infected at MOI of 50:1. B. abortus 2308 (open triangle), B. abortus $\Delta f l g J$ (open square), and complemented B. abortus $\Delta f l g J$ (pBV1-flgJ) (closed square). (B) HeLa cells were infected at MOI of 500:1. Results correspond to a representative experiment from two separate experiments. For each time point and each strain results are expressed as means \pm standard deviation. ${ }^{*} P<0.05$ when compared to parental B. abortus 2308.

within HeLa cells was analyzed, all the strains showed a similar number of intracellular bacteria between $4 \mathrm{~h}\left(2.3 \log _{10} \mathrm{CFU}\right.$ $\mathrm{ml}^{-1}$ ) and $24 \mathrm{~h}\left(2.9 \log _{10} \mathrm{CFU} \mathrm{ml} \mathrm{m}^{-1}\right)$ p.i. (Figure $\left.4 \mathrm{~B}\right)$. However, between 48 and $72 \mathrm{~h}$ p.i. the $B$. abortus $\Delta$ flgJ mutant was

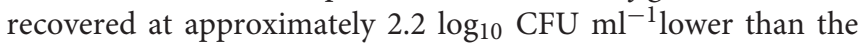
parental and complemented strains $(P>0.05)$ (Figure 4). These results indicate that the absence of the flgJ gene in $B$. abortus makes it more sensitive to its intracellular survival.

\section{Effect of the Deletion of the Gene flgJ in Intracellular Traffic}

To study the effect of the elimination of the flgJ gene in intracellular traffic, the protection test with gentamicin was used (Starr et al., 2008), infecting macrophages with B. abortus 2308, B. abortus $\Delta$ flgJ or the complemented strain. No significant differences were seen at $15 \mathrm{~min}$ p.i. between, B. abortus 2308 and $B$. abortus $\Delta$ flgJ $(P>0.05)$, since they both showed similar percentages of co-localization with the early endosome marker EEA1 (39\% and 42\% for B. abortus 2308 and B. abortus $\Delta$ flgJ, respectively) (Figure 5A). Then, at $4 \mathrm{~h}$ p.i. no significant difference in co-localization with late endosome marker LAMP1 was found between B. abortus 2308 (23\%) and B. abortus $\Delta$ flgJ (11\%) $(P>0.05)$ (Figure 5B). Interestingly, in contrast to the wild-type strain, $B$. abortus $\Delta$ flgJ did not significantly colocalize with the ER marker calnexin protein at $12 \mathrm{~h}$ p.i. $(P$ $<0.05$ ) (Figure 5C). No difference in intracellular trafficking was observed between the wild-type and B. abortus $\Delta$ flgJ (pBV1$f l g J)$. These data suggest that the flgJ mutant was prevented from reaching the ER, which is fundamental to intracellular survival of B. abortus 2308 .

\section{Survival of $B$. abortus $2308 \Delta f l g J$ in Mice}

The effect of the flgJ gene deletion on bacterial virulence was determined, analyzing the bacterial loads present in the spleens of infected mice. We found that the survival of B. abortus 2308 $\Delta f l g J$ in mouse spleen was significantly reduced after the 4 weeks p.i. from $6.28 \pm 0.39 \log _{10} \mathrm{CFU} /$ spleen in the second week p.i. to $3.22 \pm 0.07 \log _{10} \mathrm{CFU} /$ spleen in the fourth week p.i. $(P<$ 0.05). Compared to the wild-type strain, the reduction was 1.22 $\log _{10} \mathrm{CFU} /$ spleen units at 4 weeks p.i. (Table 3). On the other hand, there were significant differences in the persistence of the B. abortus $2308 \Delta$ flgJ mutant and the complemented strain at 4 weeks (Table 3). These are compelling data that suggest that the presence of the FlgJ protein is important for bacterial persistence in $\mathrm{BALB} / \mathrm{c}$ mice.

\section{DISCUSSION}

The flagellum is an important virulence factor used for motility of various pathogenic bacteria to reach their specific infection site, avoiding hostile environments and accessing nutrients (Moens and Vanderleyden, 1996). It has been demonstrated that the flagellar system is essential for the infectious cycle and persistence of Brucella in mammalian hosts (Fretin et al., 2005; Zygmunt et al., 2006; Al Dahouk et al., 2017). A polar flagellum has been identified in B. melitensis, which is expressed under very specific infection conditions (Briones et al., 2001). The importance of this macrostructure in the physiology or pathogenicity of Brucella species has not been described; However, B. melitensis mutant strains for some flagellar proteins such as $f l i f, f l h A, \operatorname{mot} B$, or $f l g E$ are less able to survive intracellularly in mouse spleen than the parental strain (Fretin et al., 2005). Although B. abortus contains all the genes for a functional flagellum, it has not yet been described yet. However, this bacterium possesses a flagellar-peptidoglycan hydrolase FlgJ in the GI-3, which could be involved in the virulence of this species (Li et al., 2012). Based on this information, in this study the open reading frame BAB1_0260, encoding for the flagellar FlgJ protein, from $B$. abortus 2308 was deleted to evaluate if its product is involved in the virulence of this bacterium (Ratushna et al., 2006; He and Xiang, 2010; Zhang et al., 2012).

Here we demonstrated that the deletion of FlgJ, a protein involved in the flagellum assembly and PG-remodeling, was not lethal for the B. abortus strain. This protein has a N-terminal half with function scaffold or cap essential for flagellar rod assembly and a C-terminal half with peptidoglycan (PG)-hydrolyzing activity that facilitates the rod penetration into the PG (Nambu et al., 1999; Hirano et al., 2001). This hydrolase function makes it possible to remodel the PG and it facilitates the passage of the flagellum (rod) through of the $\beta$-N-acetylglucosamine and 
A
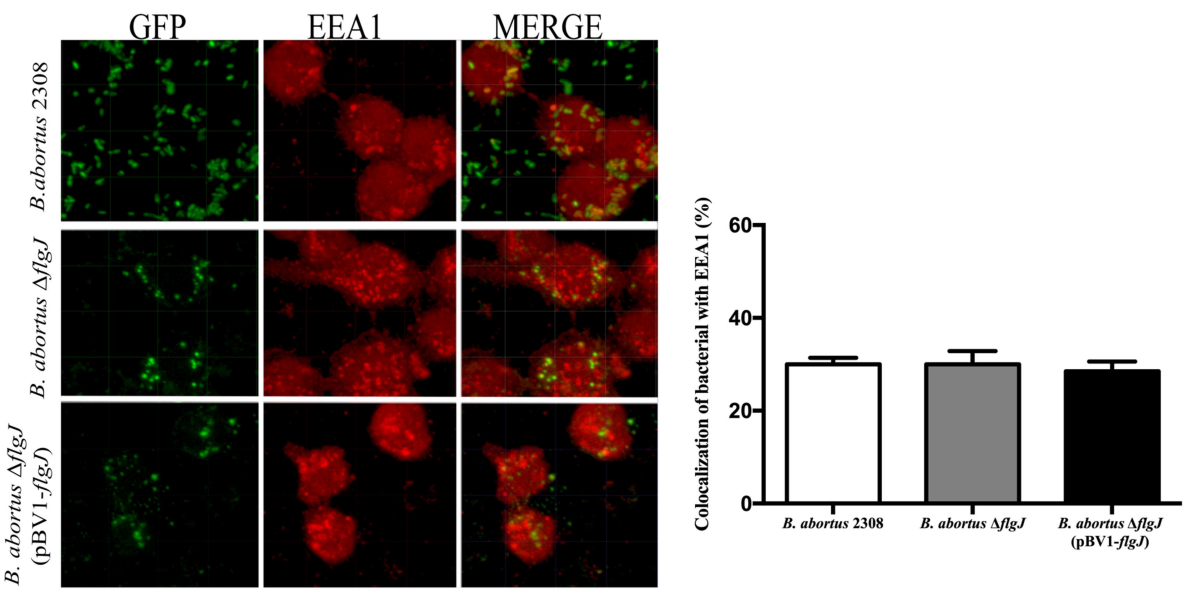

B
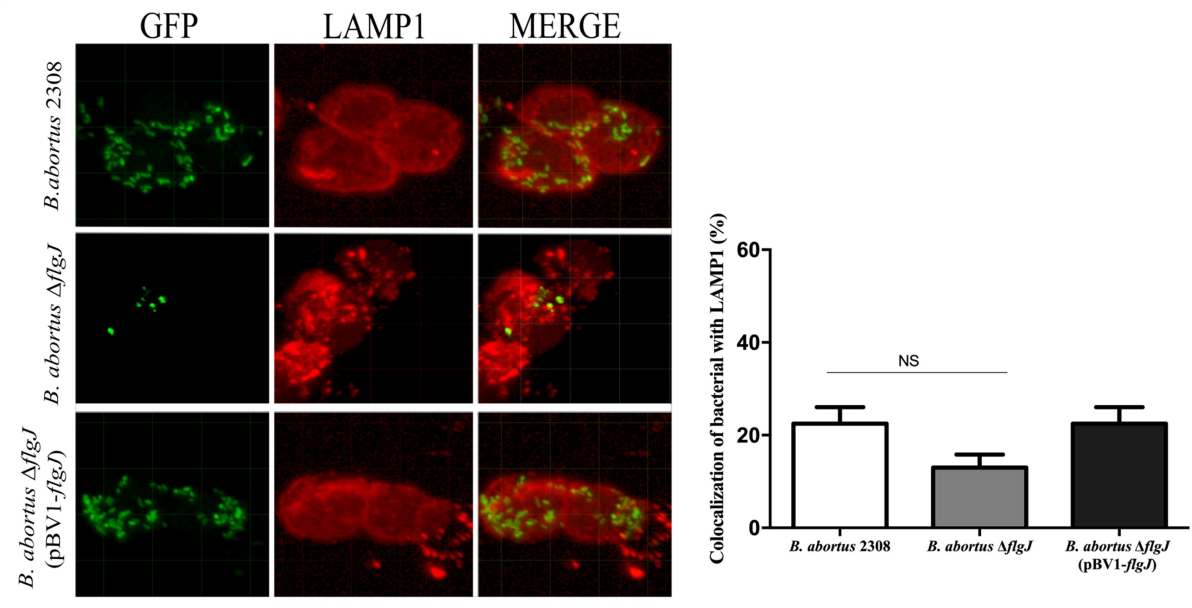

C
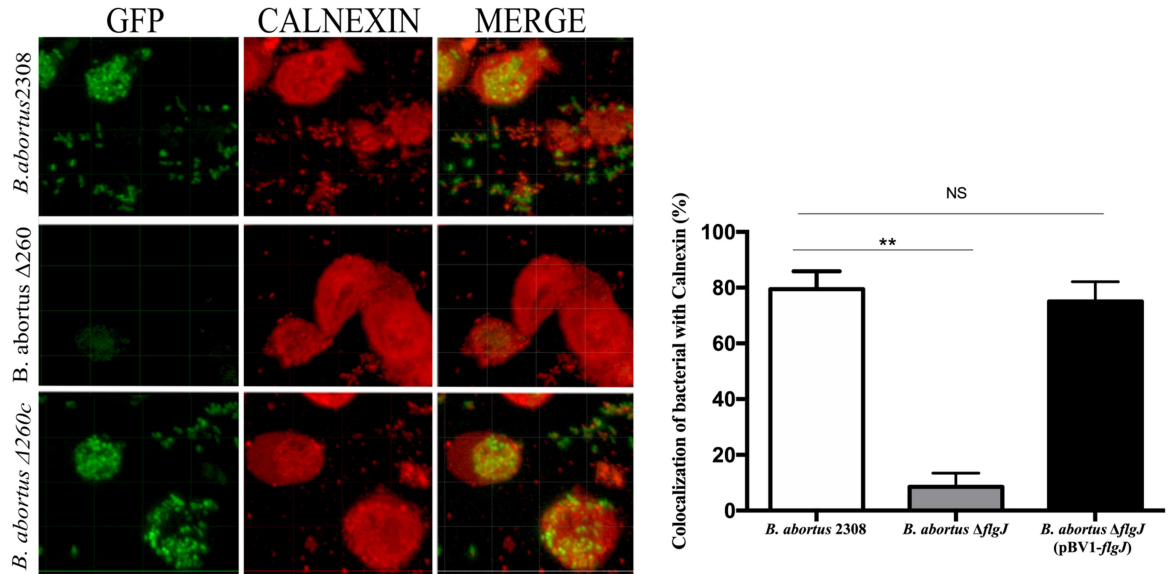

FIGURE 5 | Intracellular trafficking of B. abortus $2308 \Delta f l g J$ in macrophages. Murine macrophages RAW264.7 were infected with the Brucella strains at MOI of 50:1. Representative confocal image showing the co-localization of B. abortus 2308-gfp, B. abortus $\Delta f l g J$-gfp and B. abortus $\Delta f l g J$ (pBV1-flgJ)-gfp strains with EEA1 protein (A), LAMP1 protein (B), and calnexin protein (C). Results were expressed as mean \pm standard deviation (SD), ${ }^{* \star} P<0.01$ significant. 
TABLE 3 | Spleen colonization of BALB/c mice with B. abortus wild-type 2308, B. abortus $2308 \Delta f l g J$ mutant, and complemented B. abortus 2308 $\Delta$ flgJ (pVB1-flgJ) strains.

\begin{tabular}{lcc}
\hline B. abortus strains & $\begin{array}{c}\text { Two-weeks post } \\
\text { infection }\end{array}$ & $\begin{array}{c}\text { Four-weeks post } \\
\text { infection }\end{array}$ \\
\hline B. abortus 2308 & $5.95 \pm 0.16$ & $4.44 \pm 0.56$ \\
B. abortus 2308 $\Delta$ flgJ & $6.28 \pm 0.39$ & $3.22 \pm 0.07^{\star}$ \\
B. abortus 2308 $\Delta$ flgJ (pVB1-flgJ) & $6.24 \pm 0.51$ & $3.80 \pm 0.76$ \\
\hline
\end{tabular}

$\log _{10} C F U$ of $B$. abortus strains in the spleens of BALB/C mice infected intraperitoneally with $5 \times 10^{4}$ CFU wild-type B. abortus 2308, B. abortus 2308 AflgJ mutant or complemented B. abortus $2308 \Delta \mathrm{flgJ}$ (pVB1-flgJ) strains. Statistical analyses were made comparing mutant with wild type and complemented strains. ${ }^{*} P<0.05$ showing a number significantly less of CFU/spleen compared to B. abortus 2308.

$\beta$-N-acetylmuramic acid sugars (Hirano et al., 2001; Zaloba et al., 2016). Furthermore, it has been reported that bacteria mutants for flgJ fail to produce periplasmic and external flagellar components such as the rods, hooks (FlgE) or filaments (FlaB, in $B$. abortus is called $\mathrm{FliC}$ ) proteins due to their peptidoglycan hydrolase activity, which is necessary to penetrate the PG layer during flagellar formation, but it is also required for the cell growth and division (Vollmer et al., 2008; Zhang et al., 2012). Interestingly, a comparative analysis shows that, although $B$. abortus FlgJ differs in the length of amino acid sequences, it contains the same domains involved in the rod assembly and in the PG-hydrolyzing activity (glucosaminidase and LYZ2) as the flagellar FlgJ protein of E. coli (Marchler-Bauer et al., 2017).

Considering that B. abortus is a "non-mobile" bacterium, the hydrolyzing activity of FlgJ over the PG could play an important role in the growth of this bacterium, specifically during the remodeling of the PG during its cell division, which would explain why deletion of the flgJ gene significantly reduced its growth, which was observed by a decreased ability to adapt to the lag phase and at the beginning of the exponential phase. Furthermore, although the deletion of the flgJ gene showed an important role in the adherence to the polystyrene surface, which would demonstrate that FlgJ participates in the adherence or in the secretion of proteins involved in the process, is highly probable that the biomass adhering of B. abortus 2308 $\mathrm{flgJ}$ is directly correlated to the levels of bacterial growth and division. A reduced bacterial adherence would affect negatively the colonization of the host's tissues, where several factors participate, including the flagellum (Klemm et al., 2010). In this process, several bacteria produce biofilm, a structure that has not been described in B. abortus, but which is associated with the same Quorum Sensing signals (VjbR) involved in the expression of the flagellar genes in B. melitensis (Taminiau et al., 2002; Delrue et al., 2005). Finally, deletion of $\mathrm{flgJ}$ gene in E. coli K-12, a flagellated bacterium, abolished its movement. Nevertheless, it was slightly restored by the complementation with the B. abortus flgJ gene. This may have occurred due to a possible structural and functional similarity between these two phylogenic distant proteins, which was supported by slight growth in vitro of $E$. coli flgJ complemented strain. Therefore, the deletion of the $f l g J$ reduces the biomass adhering and motility, however, the flagellar production and motility are downregulated in the biofilm cells (Rossi et al., 2018). These observations would support the idea that the biomass adhering of $B$. abortus $2308 \mathrm{flgJ}$ is associated to bacterial growth and division, being evident that FlgJ would participate in the normal life cycle of B. abortus 2308 .

The effect of FlgJ in the physiology of the $B$. abortus mutant strain for flgJ gene was affected, reducing significantly intracellular survival in professional and non-professional phagocytic cells. This ability of $B$. abortus is similar to that described for mutant strains whose genes are encoded in genomic island 3 of B. abortus (GI-3), a genomic segment the FlgJ protein is encoded (Céspedes et al., 2011; Ortiz-Román et al., 2014). In addition, in epithelial cells and macrophages $B$. abortus mutant for the FlgJ protein was unable to reach its replicative niche, which is associated with the endoplasmic reticulum (de Bagues Maria-Pilar et al., 2005). In the first instance, this leads us to think that FlgJ is a virulence factor whose deletion in this mutant strain makes it more susceptible to be carried toward the lysosomal compartments and its subsequent degradation. This lysosomal degradation pathway has also been reported in several Brucella mutants for important virulence factors such as, cyclic $\beta-1,2-$ glucans $(\mathrm{C} \beta \mathrm{Gs})$, LPS or virB genes codifying of the type IV secretion system (Celli et al., 2003; Haag et al., 2010; Gomes et al., 2013). This subcellular compartment (ER) was achieved by $B$. abortus wild type at 12 p.i.; however, the B. abortus mutant for FlgJ simultaneously showed a reduced capacity to replicates in this compartment of the host's eukaryotic cells. consequently, a high number of bacteria is degraded by the macrophages. This is how the deletion of FlgJ affects the fitness of B. abortus. Based on our results, we believe that FlgJ hydrolase activity is required for the basic physiology of this bacterium, likely during the cellular infection process, which negatively affect the capacity of $B$. abortus to escape from the endosomal/phagolysosomal pathway and develop a replicative niche in macrophages, which allows it to survive and replicate intracellularly in eukaryotic cells.

The cellular infection models were positively correlated with the infection of mice, where the mutant B. abortus $2308 \Delta$ flgJ strain, compared with $B$. abortus 2308 and B. abortus $\Delta$ flgJ (pBV1-flgJ) complemented strain, was significantly eliminated from spleen of mice at 4 weeks p.i. because mutant strains for FlgJ reduces the expression of FlaB (FliC in Brucella), a protein of flagellum filament in Borrelia burgdorferi (Zhang et al., 2012), it would be expected that periplasmic or filament FliC protein of Brucella, would not be expressed during the infection of mice. In $B$. melitensis, the expression and recognizing of FliC protein determine the activation of the innate immune response and modulates the systemic persistence of Brucella during the infection (Terwagne et al., 2013). Besides, differences between in vivo and in vitro assays were observed, where $B$. abortus was remain for longer period of time in mice than macrophages or epithelial cells. These results would depend of innate immune sensors for flagellar protein, where FliC is targeted for the cytosolic receptor NLRC4 during infection of mice; while, alternative pathways could recognize this protein in macrophages cultured in vitro (Terwagne et al., 2013). Furthermore, it has been reported that in vivo infections can be more persistent than in vitro, because $B$. abortus establishes 
a persistent infection in a "protected niche" (e.g., B cells) that obstructed an effective immune response within the host or by the formation of granulomas where bacteria persisted in spleen (Goenka et al., 2012; Grilló et al., 2012). Furthermore, at 4 weeks p.i. the complemented strain had a lower response in comparison than wild type, but higher than the mutant strain, a tendency to lose its capacity for infection and persistence in the host as well as B. abortus $\Delta f l g J$. This may be because the mice were not treated with ampicillin, an antibiotic required for maintenance of plasmid complementation, which was not used because it could not reach the concentration required at the infection site, cross the host's cell membranes or because the mice treated were able to change their natural microbiota, thereby altering the results (Krute et al., 2016). Consequently, these results demonstrate that FlgJ is an important protein in the virulence of this pathogen and that this flagellar protein of B. abortus is similar to the results reported for several mutants for flagella structural proteins such as the MS ring (FliF), the P ring (FlgI) and the filament (FliC) during the infection process of mice (Fretin et al., 2005).

Therefore, the results demonstrate that the flgJ gene product (FlgJ protein) significantly contributed to the virulence of $B$. abortus strain 2308, supporting the hypothesis that the absence of the FlgJ flagellar protein affects intracellular survival of B. abortus 2308 and the establishment of a systemic infection in a murine model. Therefore, assuming that this protein acts in the assembly of a polar flagellum, several questions arise regarding its functions during infection or perhaps in the secretion of proteins such as a type 3 secretion system (T3SS), which has not been described in these bacteria (Ratushna et al., 2006). Based on the results described here, we can demonstrate that flgJ, a gene encoded by the ORF BAB1_0260 conserved in the GI-3, contributes to the fitness of $B$. abortus, which significantly reduced its virulence in in vitro and in vivo experimental models.

\section{CONCLUSION}

With these results it can be pointed out that FlgJ (BAB1_0260) is a protein that participates in many important processes in Brucella

\section{REFERENCES}

Abdallah, A. I., Commander, N. J., Woodward, M. J., Spencer, S., Hart, C. A., and Winstanley, C. (2003). Type III secretion homologs are present in Brucella melitensis, B. ovis, and B. suis biovars 1, 2, and 3. Curr. Microbiol. 46, 241-245. doi: 10.1007/s00284-002-3789-3

Al Dahouk, S., Köhler, S., Occhialini, A., Jiménez de Bagüés, M. P., Hammerl, J. A., Eisenberg, T., et al. (2017). Brucella spp. of amphibians comprises genomically diverse motile strains competent for replication in macrophages and survival in mammalian hosts. Sci. Rep. 7:44420. doi: 10.1038/srep44420

Almirón, M. A., Roset, M. S., and Sanjuan, N. (2013). The aggregation of Brucella abortus occurs under microaerobic conditions and promotes desiccation tolerance and biofilm formation. Open Microbiol. J. 22, 87-91. doi: $10.2174 / 1874285801307010087$

Altamirano-Silva, P., Meza-Torres, J., Castillo-Zeledón, A., Ruiz-Villalobos, N., Zuñiga-Pereira, A. M., Chacón-Díaz, C., et al. (2018). Brucella abortus senses the intracellular environment through the BvrR/BvrS two-component system, which allows $B$. abortus to adapt to its replicative niche. Infect. Immun. 86, 713-717. doi: 10.1128/IAI.00713-17 abortus 2308 infection events and in establishing of a replicative niche, mobility and biomass production, which are essential to colonization of the host cell.

\section{DATA AVAILABILITY STATEMENT}

The datasets generated for this study are available on request to the corresponding author.

\section{ETHICS STATEMENT}

The animal study was reviewed and approved by Institutional Bioethics Committee of the Universidad de Concepción and the Bioethics and Security Committee of the Faculty of Biological Sciences in the Universidad de Concepción.

\section{AUTHOR CONTRIBUTIONS}

RC-R writing and discussion of the result, survivor intracellular experiment, evaluation of biofilms. LG bacterial colonization assay and statistical analysis of the results. FA study of intracellular traffic by confocal microscopy. WS construction of mutants. FC construction of recombinant plasmid and evaluation of motility assay. SC bacterial colonization assay. RV review and proposal of conclusions. AO programming and monitoring the experiment, performing the analysis and discussion, writing the manuscript and principal investigator at the FONDECYT grant that funded this work.

\section{FUNDING}

This work was supported by Grant 1180122 from the Fondo Nacional de Desarrollo Científico y Tecnológico (FONDECYT), Santiago, Chile. LG was a recipient of a CONICYT scholarship for Ph.D. students in Chile.

Blocker, A., Komoriya, A., and Aizawa, S. (2003). Type III secretionsystemsandbacterial flagella: insights into their function from structural similarities. Proc. Natl. Acad. Sci. U.S.A. 100, 3027-3030. doi: $10.1073 /$ pnas. 0535335100

Briones, G., Iñón de Iannino, N., Roset, M., Vigliocco, A., Paulo, P. S., and Ugalde, R. A. (2001). Brucella abortus cyclic beta-1,2-glucan mutants have reduced virulence in mice and are defective in intracellular replication in HeLa cells. Infect. Immun. 69, 4528-4535. doi: 10.1128/IAI.69.7.4528-4535.2001

Burmølle, M., Thomsen, T. R., Fazli, M., Dige, I., Christensen, L., Homøe, P., et al. (2010). Biofilms in chronic infections a matter of opportunity monospecies biofilms in multispecies infections. FEMS Immunol. Med. Microbiol. 59, 324-336. doi: 10.1111/j.1574-695X.2010.00714.x

Carvalho, A. V., Mol, J. P., Xavier, M. N., Paixáo, T. A., Lage, A. P., and Santos, R. L. (2010). Pathogenesis of bovine brucellosis. Vet. J. 184,146-155. doi: 10.1016/j.tvjl.2009.04.010

Celli, J., de Chastellier, C., Franchini, D. M., Pizarro-Cerda, J., Moreno, E., and Gorvel, J. P. (2003). Brucella evades macrophage killing via VirB-dependent sustained interactions with the endoplasmic reticulum. J. Exp. Med. 198, 545-556. doi: 10.1084/jem.20030088 
Céspedes, S., Salgado, P., Retamal-Díaz, A., Vidal, R., and Oñate, A. (2012). Roles of genomic island 3 (GI-3) BAB1_0278 and BAB1_0263 open reading frames (ORFs) in the virulence of Brucella abortus in BALB/c mice. Vet. Microbiol. 23, 156-163. doi: 10.1016/j.vetmic.2011.09.025

Céspedes, S., Salgado, P., Valenzuela, P., Vidal, R., Oñate, A. A.Céspedes, S., Salgado, P., et al. (2011). Characterization of genomic island 3 and genetic variability of Chilean field strains of Brucella abortus. J. Clin. Microbiol. 49, 2461-2470. doi: 10.1128/JCM.01176-10

Chai, F. P., Kasing, A., Jennifer, J., Lesley, M., Lela, S., et al. (2017). Microtitre plate assay for the quantification of biofilm formation by pathogenic Leptospira. Res. J. Microbiol. 12, 146-153. doi: 10.3923/jm.2017.146.153

Cirl, C., Wieser, A., Yadav, M., Duerr, S., Schubert, S., Fischer, H., et al. (2008). Subversion of toll-like receptor signaling by a unique family of bacterial toll/interleukin-1 receptor domain-containing proteins. Nat. Med. 14, 399-406. doi: 10.1038/nm1734

Corbel, M. J. (1997). Brucellosis: an overview. Emerg. Infect. Dis. 3, 213-221. doi: 10.3201/eid0302.970219

D’Anastasio, R., Staniscia, T., Milia, M. L., Manzoli, L., and Capasso, L. (2011). Origin evolution and paleoepidemiology of brucellosis. Epidemiol. Infect. 139, 149-156. doi: 10.1017/S095026881000097X

Datsenko, K. A., and Wanner, B. L. (2000). One-step inactivation of chromosomal genes in Escherichia coli K-12 using PCR products. Proc. Natl. Acad. Sci. U.S.A. 97, 6640-6645. doi: 10.1073/pnas.120163297

de Bagues Maria-Pilar, J., Dudal, S., Dornand, J., and Gross, A. (2005). Cellular bioterrorism: how Brucella corrupts macrophage physiology to promote invasion and proliferation. Clin. Immun. 114, 227-238. doi: 10.1016/j.clim.2004.07.010

De Figueiredo, P., Fitch, T., Rice-Fitch, A., Rossetti, C. A., and Adams, L. G. (2015). Pathogenesis and immunobiology of brucellosis review of Brucella-host interactions. Am. J. Pathol. 85, 1505-1522. doi: 10.1016/j.ajpath.2015.03.003

Dean, A. S., Schelling, E., Bonfoh, B., Kulo, A. E., Boukaya, G. A., and Pilo, P. (2014). Deletion in the Gene BruAb2_0168 of Brucella abortus strains: diagnostic challenges. Clin. Microbiol. Infect. 20, 550-553. doi: 10.1111/1469-0691.12554

Delrue, R. M., Deschamps, C., Léonard, S., Nijskens, C., Danese, I., Schaus, J. M., et al. (2005). A quorum-sensing regulator controls expression of both the type IV secretion system and the flagellar apparatus of Brucella melitensis. Cell. Microbiol. 7, 1151-1161. doi: 10.1111/j.1462-5822.2005.00543.x

Flemming, H., and Wingender, J. (2010). The biofilm matrix. Nat. Rev. Microbiol. 8, 623-633. doi: 10.1038/nrmicro2415

Fretin, D., Fauconnier, A., Köhler, S., Halling, S., Léonard, S., Nijskens, C., et al. (2005). The sheathed flagellum of Brucella melitensis is involved in persistence in a murine model of infection. Cell. Microbiol. 7, 687-698. doi: 10.1111/j.1462-5822.2005.00502.x

Galinska, E. M., and Zagórski, J. (2013). Brucellosis in humans-etiology, diagnostics, clinical forms. Ann. Agric. Environ. Med. 20, 233-241.

Goenka, R., Guirnalda, P. D., Black, S. J., and Baldwin, C. L. (2012). B lymphocytes provide an infection niche for intracellular bacterium Brucella abortus. J. Infect. Dis. 206, 91-98. doi: 10.1093/infdis/jis310

Gomes, M. T., Campos, P. C., Oliveira, F. S., Corsetti, P. P., Bortoluci, K. R., Cunha, L. D., et al. (2013). Critical role of ASC inflammasomes and bacterial type IV secretion system in caspase-1 activation and host innate resistance to Brucella abortus infection. J. Immunol. 190, 3629-3638. doi: 10.4049/jimmunol.1202817

Gómez, L., Álvarez, F., and Betancur, D., Oñate, A. (2018). Brucellosis vaccines based on the open reading frames from genomic island 3 of Brucella abortus. Vaccine 17, 2928-2936. doi: 10.1016/j.vaccine.2018. 04.014

Gómez, L., Alvarez, F., Fernández, P., Flores, M., Molina, R., Coloma R. F., et al. (2016). Immunogenicity and Protective Response Induced by Recombinant Plasmids Based on the BAB1_0267 and BAB1_0270 Open Reading Frames of Brucella abortus 2308 in BALB/c Mice. Front. Cell Infect. Microbiol. 6:217. doi: 10.3389/fcimb.2016.00117

Grilló, M. J., Blasco, J. M., Gorvel, J. P., Moriyón, I., and Moreno, E. (2012). What have we learned from brucellosis in the mouse model? Vet. Res. 43:29. doi: 10.1186/1297-9716-43-29

Haag, A. F., Myka, K. K., Arnold, M. F., Caro_Hernández, P., and Ferguson, G. P. (2010). Importance of lipopolysaccharide and cyclic $\beta$-1-2glucan in brucellamammalian infection. Int. J. Microbiol. 2010:124509. doi: 10.1155/2010/124509
Haiko, J., and Westerlund-Wikström, B. (2013). The Role of the bacterial flagellum in adhesion and virulence. Biology 25, 1242-1267. doi: 10.3390/biology2041242

Halling, S. M. (1998). On the presence and organization of open reading frames of the nonmotile pathogen Brucella abortus similar to class II, III, and IV flagellar genes and to LcrD virulence superfamily. Microb. Comp. Genomics. 3, 21-29. doi: 10.1089/omi.1.1998.3.21

Hall-Stoodleyl, L., and Stoodley, P. (2009). Evolving concepts in biofilm infections. Cell. Microbiol. 11, 1034-1043. doi: 10.1111/j.1462-5822.2009.01323.x

He, Y., and Xiang, Z. (2010). Bioinformatics analysis of Brucella vaccines and vaccine targets using VIOLIN. Inmunome 27 (Suppl. 1), S5. doi: 10.1186/1745-7580-6-S1-S5

Hirano, T., Minamino, T., and Macnab, R. M. (2001). The role in flagellar rod assembly of the N-terminal domain of Salmonella FlgJ, a flagellum specific muramidase. J. Mol. Biol. 312, 359-369. doi: 10.1006/jmbi.2001.4963

Josenhans, C., and Suerbaum, S. (2002). The role of motility as a virulence factor in bacteria. Int. J. Med. Microbiol. 291, 605-614. doi: 10.1078/1438-4221-00173

Klemm, P., Vejborg, R. M., and Hancock, V. (2010). Prevention of bacterial adhesion. Appl. Microbiol. Biotechnol. 88, 451-459. doi: 10.1007/s00253-010-2805-y

Krute, C. N., Krausz, K. L., Markiewicz, M. A., Joyner, J. A., Pokhrel, S., Hall, P. R., et al. (2016). Generation of a stable plasmid for in vitro and in vivo studies of Staphylococcus species. Appl. Environ. Microbiol. 82, 6859-6869. doi: 10.1128/AEM.02370-16

Li, X., Xu, J., Xie, Y., Qiu, Y., Fu, S., Yuan, X., et al. (2012). Vaccination with recombinant flagellar proteins FlgJ and FliN induce protection against Brucella abortus 544 infection in BALB/c mice. Vet. Microbiol. 161,137-144. doi: 10.1016/j.vetmic.2012.07.016

Marchler-Bauer, A., Bo, Y., Han, L., He, J., Lanczycki, C. J., Lu, S., et al. (2017). CDD/SPARCLE: functional classification of proteins via subfamily domain architectures. Nucleic Acids Res. 45, 200-203. doi: 10.1093/nar/gkw1129

Moens, S., and Vanderleyden, J. (1996). Functions of bacterial flagella. Crit. Rev. Microbiol. 22, 67-100. doi: 10.3109/10408419609106456

Nambu, T., Minamino, T., Macnab, R. M., and Kutsukake, K. (1999). Peptidoglycan-hydrolyzing activity of the FlgJ protein, essential for flagellar rod formation in Salmonella typhimurium. J. Bacteriol. 181, 1555-1561. doi: 10.1128/JB.181.5.1555-1561.1999

Ortiz-Román, L., Riquelme-Neira, R., RobertoVidal, and Oñate, A. (2014). Roles of genomic island 3 (GI-3) BAB1_0267 and BAB1_0270 open reading frames (ORFs) in the virulence of Brucella abortus 2308. Vet. Microbiol. 172, 279-284. doi: 10.1016/j.vetmic.2014.05.005

Rajashekara, G., Glasner, J. D., Glover, D. A., and Splitter, G. A. (2004). Comparative whole-genome hybridization reveals genomic islands in Brucella species. J. Bacteriol. 186, 5040-5051. doi: 10.1128/JB.186.15.5040-5051.2004

Rambow-Larsen, A. A., Rajashekara, G., Petersen, E., and Splitter, G. (2008). Putative quorum-sensing regulator BlxR of Brucella melitensis regulates virulence factors including the type IV secretion system and flagella. J. Bacteriol. 190, 3274-3282. doi: 10.1128/JB.01915-07

Ratushna, V. G., Sturgill, D. M., Ramamoorthy, S., Reichow, S. A., He, Y., Lathigra, R., et al. (2006). Molecular targets for rapid identification of Brucella spp. BMC Microbiol. 6:13. doi: 10.1186/1471-2180-6-13

Rossi, E., Paroni, M., and Landini, P. (2018). Biofilm and motility in response to environmental and host-related signals in gram negative opportunistic pathogens. J. Appl. Microbiol. 125, 1587-1602. doi: 10.1111/jam. 14089

Salcedo, S. P., Marchesini, M. I., Lelouard, H., Fugier, E., Jolly, G., Balor, S., et al. (2008). Brucella control of dendritic cell maturation is dependent on the TIR-containing protein Btp1. PLoS Pathog. 4:e21. doi: 10.1371/journal.ppat. 0040021

Sharan, S. K., Thomason, L. C., Kuznetsov, S. G., Court, D. L.Sharan, S. K., Thomason, L. C., Kuznetsov, S. G., et al. (2009). Recombineering: a homologous recombination-based method of genetic engineering. Nat. Protoc. 4, 206-223. doi: 10.1038/nprot.2008.227

Spanò, A., Laganà, P., Visalli, G., Maugeri, T. L., and Gugliandolo, C. (2016). In Vitro antibiofilm activity of an exopolysaccharide from the marine thermophilic Bacillus licheniformis T14. Curr. Microbiol. 72, 518-528. doi: 10.1007/s00284-015-0981-9

Starr, T., Ng, T. W., Wehrly, T. D., Knodler, L. A., and Celli, J. (2008). Brucella intracellular replication requires trafficking through 
the late endosomal/lysosomal compartment. Traffic 9, 678-694. doi: 10.1111/j.1600-0854.2008.00718.x

Stepanović, S., Vuković, D., Hola, V., Di Bonaventura, G., Djukić, S., Cirković, I., et al. (2007). Quantification of biofilm in microtiter plates: overview of testing conditions and practical recommendations for assessment of biofilm production by staphylococci. APMIS 115, 891-899. doi: 10.1111/j.1600-0463.2007.apm_630.x

Taminiau, B., Daykin, M., Swift, S., Boschiroli, M. L., Tibor, A., Lestrate, P., et al. (2002). Identification of a quorum-sensing signal molecule in the facultative intracellular pathogen Brucella melitensis. Infect. Immun. 70, 3004-3011. doi: 10.1128/IAI.70.6.3004-3011.2002

Terwagne, M., Ferooz, J., Rolan, H. G., Sun, Y. H., Atluri, V., Xavier, M. N., et al. (2013). Innate immune recognition of flagellin limits systemic persistence of Brucella. Cell Microbiol. 15, 942-960. doi: 10.1111/cmi.12088

Vollmer, W., Joris, B., Charlier, P., and Foster, S. (2008). Bacterial peptidoglycan (murein) hydrolases. FEMS Microbiol. Rev. 32, 259-286. doi: 10.1111/j.1574-6976.2007.00099.x

Young, E. J., Hasanjani Roushan, M. R., Shafae, S., Genta, R. M., and Taylor, S. L. (2014). Liver histology of acute brucellosis caused by Brucella melitensis. Hum. Pathol. 45, 2023-2031. doi: 10.1016/j.humpath.2014.07.007

Zaloba, P., Bailey-Elkin, B. A., Derksen, M., and Mark, B. L. (2016). Structural and biochemical insights into the peptidoglycan hydrolase domain of FljgJ from Salmonella typhimurium. PLoS ONE 11:2. doi: 10.1371/journal.pone.0149204
Zhang, K., Tong, B. A., Liu, J., and Li, C. (2012). A single-domain FlgJ contributes to flagellar hook and filament formation in the lyme disease spirochete Borrelia burgdorferi. J. Bacteriol. 194, 866-874. doi: 10.1128/JB.06341-11

Zygmunt, M. S., Hagius, S. D., Walker, J. V., and Elzer, P. H. (2006). Identification of Brucella melitensis $16 \mathrm{M}$ genes required for bacterial survival in the caprine host. Microbes Infect. 8, 2849-2854. doi: 10.1016/j.micinf.2006. 09.002

Zygmunt, M. S., Jacques, I., Bernardet, N., and Cloeckaert, A. (2012). Lipopolysaccharide heterogeneity in the atypical group of novel emerging Brucella species. Clin. Vaccine Immunol. 19, 1370-1373. doi: 10.1128/CVI.00300-12

Conflict of Interest: The authors declare that the research was conducted in the absence of any commercial or financial relationships that could be construed as a potential conflict of interest.

Copyright $\odot 2020$ Coloma-Rivero, Gómez, Alvarez, Saitz, del Canto, Céspedes, Vidal and Oñate. This is an open-access article distributed under the terms of the Creative Commons Attribution License (CC BY). The use, distribution or reproduction in other forums is permitted, provided the original author(s) and the copyright owner(s) are credited and that the original publication in this journal is cited, in accordance with accepted academic practice. No use, distribution or reproduction is permitted which does not comply with these terms. 